\title{
Temperature and the progeny sex-ratio in Sciara ocellaris (Diptera, Sciaridae)
}

\author{
Rogério G. Nigro, Maria Cristina C. Campos and André Luiz P. Perondini \\ Departamento de Genética e Biologia Evolutiva, Instituto de Biociências, Universidade de São Paulo, \\ São Paulo, SP, Brazil.
}

\begin{abstract}
We found that the sex-ratio of an amphigenic strain of Sciara ocellaris varied widely from progenies with few males to progenies containing a larger proportion of males, with single-sex progenies being rare. The sex-ratio distributions were dependent on the temperature at which the stocks of flies were raised, with the sex-ratio distributions being symmetrical (i.e. about $50 \%$ males) at $18^{\circ} \mathrm{C}$ and $20^{\circ} \mathrm{C}$ while at the higher temperatures of $24^{\circ} \mathrm{C}$ and $28^{\circ} \mathrm{C}$ the distributions were skewed toward a high proportion of females with the mean proportion of males decreasing to about $30-37 \%$ per progeny. Temperature-shift experiments showed that high temperatures were effective only during the last stages of female pupal development plus a period after adult emergence, stages corresponding to oocyte maturation. When imagine females were exposed to temperatures as low as $12^{\circ} \mathrm{C}$ the sex-ratio distributions of their progeny were skewed toward a high proportion of males per progeny. No differential fecundity was involved in these progeny sex-ratio modifications. Egg-to-adult survival was lower at $18{ }^{\circ} \mathrm{C}$ and $28^{\circ} \mathrm{C}$ but no correlations with skewing in the sex ratio distributions were observed, indicating that modifications in progeny sex-ratio did not involve the differential survival of a particular sex.
\end{abstract}

Key words: sex determination, chromosome elimination, embryo, insect.

Received: December 13, 2005; Accepted: June 22, 2006.

\section{Introduction}

It is well demonstrated that a large number of sex determination mechanisms exist among insects (White, 1973; Bull, 1983; Nothiger and Steinmann-Zwicky, 1985). In most of the species studied the signal which initiates the pathway of sex differentiation resides in the chromosomes, and hence the karyotype of the zygote established at fertilization determines the sex of the individual and also fixes the progeny sex-ratio that normally deviates only slightly from 1:1 (Bull, 1983; Crow, 1994). The initial chromosome setting, and hence the genetic constitution of the zygote, activates a cascade of genes whose function it is to determine the sex of the insect. The genes involved in this hierarchical set of sex determining genes and their functioning have been determined in Drosophila (see reviews by Sanchez et al., 1994, 1998) but differences do exist in other insects (see Müller- Holtkamp, 1995; Sievert et al., 1997; Meise et al., 1998; Saccone et al., 1998), among which are the sciarids (fungus gnat flies) Sciara ocellaris (Ruiz et al., 2003), Sciara coprophila, Rhynchosciara americana and Trichosia pubescens (Serna et al., 2004). In these species,

Send correspondence to André Luiz P. Perondini. Departamento de Genética e Biologia Evolutiva, Instituto de Biociências, Universidade de São Paulo, R. do Matão 277, 05508-900 São Paulo, SP, Brazil. E-mail: alpperon@ib.usp.br. the Sex-lethal gene does not show differential expression in males and females.

On the other hand, there are insect species in which the sex is not fixed at fertilization but is determined by the parental female by the production of oocytes containing factors that dictate the pathway for the ensuing activity of the cascade of sex determination genes. Maternal sexual predetermination does not cause sexual abnormalities in the insect and normal males or females are always produced but it does generally act on the progeny sex-ratio, by fixing the proportion of oocytes of one type or the other produced by any given female, as in Chrysomya rufifacies (Ullerich, 1975, 1984), coccids (scale insects and mealybugs; Brown and Chandra, 1977) and sciarids (Metz, 1938). Although the sexual development of each insect is rigidly controlled by the cascade of sex determination genes, the predetermination mechanisms seems to be subject to less rigid genetic control mechanism (Brown and De Lotto, 1957). Indeed, examples of alterations in progeny sex-ratio are common in coccid species in which sex predetermination mechanisms are prevalent. In these insects it has been demonstrated that a variety of biotic and abiotic agents like aging of the parental females, temperature, humidity and presence of symbionts seem to interfere with predetermination, leading to progenies with altered sexratios (Brown and Chandra, 1977). 
Two modes of sex-ratio determination are found in the Sciaridae, with females producing single-sex progeny (either males or females) in monogenic species while in digenic or amphigenic species females produce progenies with variable proportions of males and females. The monogenic Sciara coprophila and the digenic Sciara ocellaris are the two most studied species and may be taken as paradigms of these two systems. In both species, the sex of the progeny is conditioned by the parental females, that produce oocytes predetermined to develop as males or as females (reviewed by Metz, 1938; Gerbi, 1986; Perondini, 1998; Sánchez and Perondini, 1999). Sciara females mate only once, mature all their eggs simultaneously and deposit their eggs within 2-3 days and then die (Perondini, 1998), the number of eggs (200 to 250 per female) being determined at an early larval stage and no further oocytes are produced at the pupal or adult stages (Berry, 1941).

In sciarid flies although the nature of the factor (or factors) involved in the maternal predetermination of sex are still unknown the mechanism must function by the regulation of the differential elimination of paternally-derived $\mathrm{X}$ chromosomes at the beginning of embryonic development and, hence, the generation of specific male or female karyotypes (see Metz, 1938; Crouse, 1960; Gerbi, 1986; Perondini, 1998; Sánchez and Perondini, 1999). The zygotes of sciarid flies start their development with the normal double complement of each autosome but have three $\mathrm{X}$ chromosomes, two of which are of paternal origin (Metz, 1938). During the syncytial blastoderm stage one or two paternally-derived $\mathrm{X}$ chromosomes are eliminated to establish the female (XX:2A) or male (XO:2A) karyotype (DuBois, 1933; Perondini et a!., 1986). The proportion of embryos eliminating either one or two X-chromosomes determines the progeny sex-ratio. Once the specific karyotypes are established, activation of the individual sex determination mechanism seems to be accomplished by the X:A ratio, as in Drosophila (Crouse, 1960; Perondini, 1998).

As in other insect species presenting maternal sexratio predetermination, the sex of the Sciara embryos may be altered by experimental perturbations imposed on the parental females during oocyte maturation, or on the eggs before X-chromosome elimination (reviewed by Perondini, 1998; Sanchez and Perondini, 1999). In the present paper we show that temperature treatments applied to females during stages of oocyte maturation cause a preponderance of one sex or the other in their progenies, without differential survival being involved in the sex-ratio modifications.

\section{Material and Methods}

\section{Fly strain}

We used an amphigenic strain of Sciara ocellaris that has been maintained in the laboratory since 1965 (Pavan and Perondini, 1967) and which has a progeny sex-ratio varying from a few males to a preponderance of males (Mori et al., 1979). In our investigation the number of flies produced by each female also varied widely, from progenies with only a few flies (progenies with less than 30 flies were not used) to progenies with 185 flies.

\section{Constant temperature experiments}

The effect of exposure to different constant temperatures on the sex-ratio (experiment I) was studied by sampling individual pairs of matings from laboratory populations raised for several generations at $18{ }^{\circ} \mathrm{C}(80), 20{ }^{\circ} \mathrm{C}$ (148), $24^{\circ} \mathrm{C}(100)$ or $28^{\circ} \mathrm{C}(62)$, the numbers in parentheses indicating the number of females treated. The adult progeny from each individual cross was recovered, counted and the sex-ratio expressed as the percent of males. For each series of experiments the data for each parent female were grouped into sex-ratio classes of either single-sex all-female ( $0 \%$ male class) or all-male ( $0 \%$ female class) or mixed-sex progenies, the mixed-sex progenies being further grouped into five classes at $20 \%$ intervals (1 to $19 \%, \ldots$, 80 to $99 \%$ males). An experiment in which flies were maintained at $12{ }^{\circ} \mathrm{C}$ was started but then discontinued because of the exceedingly long development time, estimated at more than a year from egg to adult, and the high mortality rate. However, this low temperature was employed in the temperature-shift experiments described below.

\section{Temperature-shift experiments}

In the next series of experiments, temperature-shifts were used to determine the developmental stage during which temperature affects the sex-ratio. The temperatureshift experiments were initiated by establishing a stock of flies kept at $20{ }^{\circ} \mathrm{C}$ for three generations, flies from this stock also being used as controls.

For the temperature treatment of fertilized eggs (embryos) females from the $20^{\circ} \mathrm{C}$ stock were decapitated to induce egg deposition within 10 to 15 min (Carson, 1946, Perondini and Ribeiro, 1997) and the eggs immediately transferred to the desired temperatures. For these treatments, batches of 80 to 105 eggs produced by individual females were transferred to low $\left(12{ }^{\circ} \mathrm{C} ; 51\right.$ batches $)$ or high (24- $28^{\circ} \mathrm{C}, 52$ batches) temperatures, the latter being chosen because they gave similar results in the continuous treatment experiments described above. The embryos were transferred to the experimental temperatures at the polar body elimination stage, which occurred shortly after oviposition, and returned to the control temperature of $20^{\circ} \mathrm{C}$ before the syncytial blastoderm stage at which elimination of X-chromosomes occurs (Perondini et al, 1986), and left until the adult flies emerged, when the sex-ratio was recorded.

For the temperature treatment of females (experiments II to VII), pupae(selected based on morphology) or newly emerged imagoes were collected from the $20^{\circ} \mathrm{C}$ stock and shifted to the experimental temperature for the 
desired length of times, after which they were transferred back to $20^{\circ} \mathrm{C}$ to complete development. The emerging females were crossed to control stock $\left(20^{\circ} \mathrm{C}\right)$ males and the sex ratio of the offspring (maintained at $20^{\circ} \mathrm{C}$ ) was recorded. Two series of experiments were carried out, in one the pupae or the flies were shifted to a higher temperature $\left(24-28^{\circ} \mathrm{C}\right.$, experiments II to $\left.\mathrm{V}\right)$, while in the other experiment they were shifted to a lower temperature $\left(12^{\circ} \mathrm{C}\right.$ experiments VI and VII). For the treatment of females at the pupal or adult stages, the protocol of the temperature-shift experiments is shown in Figure 1 and the number of females treated is given in Table 1, this table also listing the different types of experiments.

\section{Fecundity, progeny survival rate and statistical analysis}

For a given number of crosses either from the constant as well as for the temperature-shift experiments we also estimated the fecundity measured as the number of eggs deposited and the progeny egg-to-adult survival rate calculated as the percentage of adult progeny that emerged from a given number of eggs (Table 1). We normalized the fecundity using a $\sqrt{ }(n+3 / 8)$ transformation and the survival rate data using an arcsine transformation. The results were analyzed using one-way analysis of variance (ANOVA) and the chi squared $\left(\chi^{2}\right)$ or Student-Newman-Keuls test (Zar, 1999). Sex-ratio distributions were compared by homogeneity testing using maximum likelihood statistics (Agresti, 1990) or the Kolmogorov-Smirnov test (Zar, 1999), considering the null hypothesis that the observed



Figure 1 - Protocol for the temperature-shift experiments with high (HT, $\left.24-28^{\circ} \mathrm{C}\right)$ or low $\left(\mathrm{LT}, 12^{\circ} \mathrm{C}\right)$ temperatures. The filled boxes indicate the periods during which the females were shifted to the experimental temperatures while the thin line represents the control temperature of $20^{\circ} \mathrm{C}$.

distributions were equal. To test possible relationships between sex-ratio and survival rates, linear regressions were calculated between the two variables.

\section{Results and Discussion}

\section{Constant temperature experiments}

The distributions of the progeny sex-ratio observed for female flies raised at different constant temperatures (experiment I) are shown in Figure 2, while female fecundity and egg-to-adult survival are shown in Table 1.

Table 1 - Parental female fecundity and progeny survival rates of crosses derived from stocks of females maintained at continuous or shifted temperatures.

\begin{tabular}{|c|c|c|c|}
\hline Experiment & Number of crosses ${ }^{*}$ & Female fecundity $^{\#}($ mean \pm SD) & Progeny survival rate ${ }^{\&}($ mean $\pm \mathrm{SD})$ \\
\hline \multicolumn{4}{|l|}{ Continuous temperature experiments (experiment I) } \\
\hline $18^{\circ} \mathrm{C}$ & 70 & $132.1 \pm 44.5$ & $46.27 \pm 16.6$ \\
\hline $20^{\circ} \mathrm{C}$ & 83 & $117.3 \pm 37.4$ & $60.43 \pm 18.4$ \\
\hline $24{ }^{\circ} \mathrm{C}$ & 32 & $114.6 \pm 29.1$ & $60.02 \pm 17.3$ \\
\hline $28^{\circ} \mathrm{C}$ & 38 & $127.5 \pm 37.1$ & $48.03 \pm 13.5$ \\
\hline \multicolumn{4}{|l|}{ Temperature-shift experiments } \\
\hline $20^{\circ} \mathrm{C}$ control & 83 & $117.3 \pm 37.4$ & $60.4 \pm 18.4$ \\
\hline \multicolumn{4}{|l|}{$24-28^{\circ} \mathrm{C}$} \\
\hline Pupal stage shifted (experiment II) & 62 & $130.0 \pm 34.2$ & $55.9 \pm 18.1$ \\
\hline $\begin{array}{l}\text { Pupal + initial period of the adult stage shifted } \\
\text { (experiment III) }\end{array}$ & 58 & $139.7 \pm 38.8$ & $54.4 \pm 24.2$ \\
\hline Pupal + whole adult stage shifted (experiment IV) & 39 & $132.0 \pm 27.2$ & $52.0 \pm 22.4$ \\
\hline adult stage shifted (experiment V) & 45 & $106.7 \pm 37.5$ & $54.9 \pm 19.0$ \\
\hline \multicolumn{4}{|l|}{$12{ }^{\circ} \mathrm{C}$} \\
\hline Females shifted at the pupal stage (experiment VI) & 50 & $121.5 \pm 30.6$ & $43.5 \pm 19.4$ \\
\hline Females shifted after emergence (experiment VII) & 54 & $121.5 \pm 36.5$ & $42.1 \pm 14.9$ \\
\hline
\end{tabular}

*Corresponding to the number of females.

${ }^{\#}$ Measured as the number of eggs deposited per female.

${ }^{\&}$ Egg-to-adult survival rate calculated as the percentage of adult progeny emerging from a given number of eggs. 


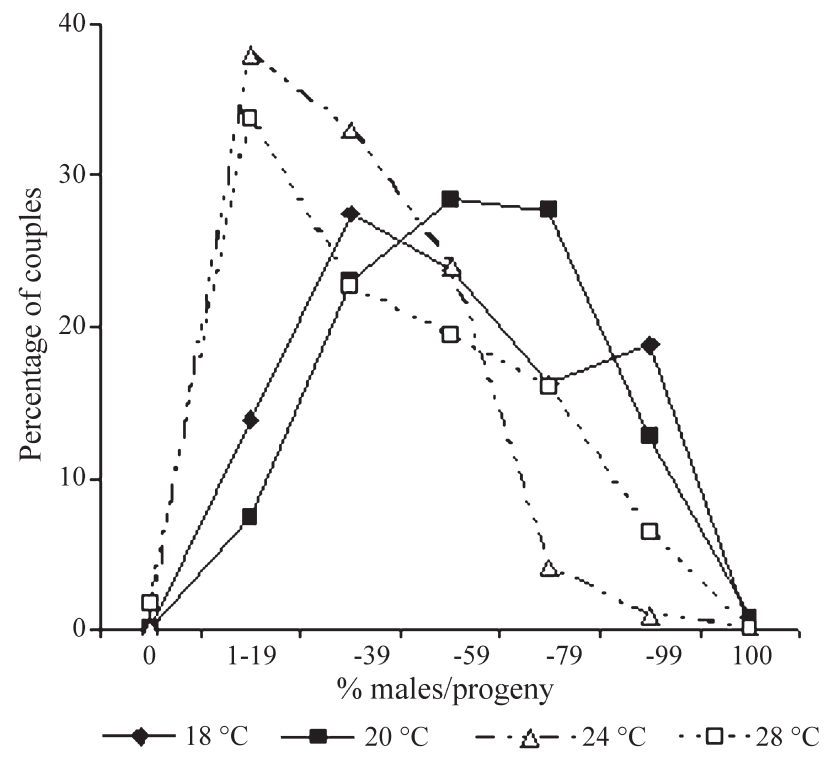

Figure 2 - Continuous temperature experiments. Frequency distributions of individual pairs of matings according to the sex-ratio of their progenies when raised at $18^{\circ}, 20^{\circ}, 24^{\circ}$ or $28^{\circ} \mathrm{C}$. The distributions at $24^{\circ} \mathrm{C}$ and $28^{\circ} \mathrm{C}$ are skewed to the left.

At all temperatures the sex-ratio (mean \pm standard deviation (SD)) was extremely variable, from progenies with very few males to those with a high proportion of males, although single-sex progenies were rare in this amphigenic strain. However, the bell-shaped sex-ratio distributions indicate temperature specific tendencies, with the sex-ratio distributions, calculated as the percentage of males ( $\mathrm{M} \%)$, of the progenies being symmetrical (non-significant at $\mathrm{p}=0.118)$ at $18{ }^{\circ} \mathrm{C}(\mathrm{M} \%=50.2 \pm 24.6)$ and $20{ }^{\circ} \mathrm{C}$ $(\mathrm{M} \%=53.4 \pm 22.7)$ while at the higher temperatures of $24{ }^{\circ} \mathrm{C}(\mathrm{M} \%=30.1 \pm 18.8)$ and $28^{\circ} \mathrm{C}(37.7 \pm 25.2)$ the distributions were asymmetric (non-significant at $\mathrm{p}=0.082$ ) and skewed towards a lower percentage of males. Homogeneity test using the maximum likelihood ratio showed that the differences between the symmetric and asymmetric distributions were highly significant $(\mathrm{p}<0.001)$.

Table 1 shows the fecundity data of the females and the egg-to-adult survival rate of the offspring from samples of crosses maintained at continuous temperatures of $18^{\circ}$, $20^{\circ}, 24^{\circ}$ or $28^{\circ} \mathrm{C}$. Statistical analysis revealed that there were no significant differences in the fecundity of females from stocks maintained at the different temperatures (ANOVA, F = 2.09 for 3, 219 degrees of freedom (df); $\mathrm{p}=0.1024)$. However, statistical differences were observed when survival rates were considered (ANOVA, $\mathrm{F}=11.53$; $\mathrm{df}=3,219 ; \mathrm{p}<0.0001)$. The Student-Newmann-Keuls test indicated that there were no significant differences in the survival rates at $18{ }^{\circ} \mathrm{C}$ as compared to $28^{\circ} \mathrm{C}$, but survival rates were significantly lower than the rates observed at $20{ }^{\circ} \mathrm{C}$ and $24{ }^{\circ} \mathrm{C}$, which did not differ from each other. To evaluate whether or not differential survival of males and females was involved in the sex-ratio modifications at the different temperatures we regressed the survival rate of each progeny against the sex-ratio for the corresponding progeny but found no differential survival in favor of males or females since the regression coefficients did not differ significantly from zero $\left(18^{\circ} \mathrm{C}: \mathrm{b}=-0.142,0.05<\mathrm{p}<0.10\right.$; $20^{\circ} \mathrm{C}: \mathrm{b}=0.074,0.20<\mathrm{p}<0.50 ; 24^{\circ} \mathrm{C}: \mathrm{b}=0.026, \mathrm{p}>0.50$; $\left.28^{\circ} \mathrm{C}: \mathrm{b}=0.107,0.20<\mathrm{p}<0.50\right)$.

Our results show that the temperature at which the Sciara ocellaris females are raised has a great influence on the sex-ratio of their progenies. At intermediate temperatures the sex-ratio distributions were symmetrical, with around 50\% males and no significant sex differences in the survival rate were observed. However, at the extreme experimental temperatures alterations in the sex-ratio were observed, together with a decrease in survival rates. The fact that survival rate was lower at the extreme temperatures of $18{ }^{\circ} \mathrm{C}$ and $28^{\circ} \mathrm{C}$ than at $20^{\circ}$ to $24^{\circ} \mathrm{C}$ is in line with what is known about metabolic alterations in insects induced by abiotic stress such as temperature. Developmental processes are at optimal levels when organisms are subjected to environmental conditions that promote minimum energy dissipation (Zotin, 1990). In Drosophila, Arking et al. (1988) found that under laboratory conditions the metabolic efficiency of females in producing an average egg is higher at $22^{\circ} \mathrm{C}$ to $25^{\circ} \mathrm{C}$ than at $18^{\circ} \mathrm{C}$ or $28^{\circ} \mathrm{C}$. Our data indicates that the fecundity of Sciara females was not affected by the whole range of temperatures tested, suggesting that physiological processes within the ovaries, and not egg production per se, was affected by the extreme temperatures and lead to the production of eggs with differential survival capacities regardless of the sex. Since we found no correlation between survival ratesand sex-ratio we concluded that differential survival between sexes is not involved in the sex-ratio modifications caused by any of the temperature treatments.

\section{Temperature-shift experiments}

At both low and high temperatures the sex-ratio distributions among the adult flies which developed from the treated embryos resulted in symmetric bell-shaped curves $\left(\mathrm{M} \%=53.1 \pm 22.5\right.$ at $12{ }^{\circ} \mathrm{C}$ and $49.3 \pm 23.2$ at $\left.24-28^{\circ} \mathrm{C}\right)$.

For the treatment of females at the pupal or adult stages, the protocol of the temperature-shift experiments is shown in Figure 1 and the number of females which were treated is given in the 'number of crosses' column in Table 1. The progeny sex-ratio distributions of females shifted to a high temperature during the pupal stage (experiment II; $\mathrm{M} \%=49.9 \pm 22.8$ ) or only at the adult stage (experiment $\mathrm{V}$; $\mathrm{M} \%=51.3 \pm 25.9)$ were symmetric but when females were shifted to high temperatures during the pupal plus an initial period of the adult stage (experiment III; M\% $\% 33.8 \pm 18.8$ ) or during the pupal plus the entire adult stage (experiment IV; $\mathrm{M} \%=41.1 \pm 26.1)$ the sex-ratio distributions were asymmetric and skewed to a lower percentage of males per progeny (Figure 3A). 

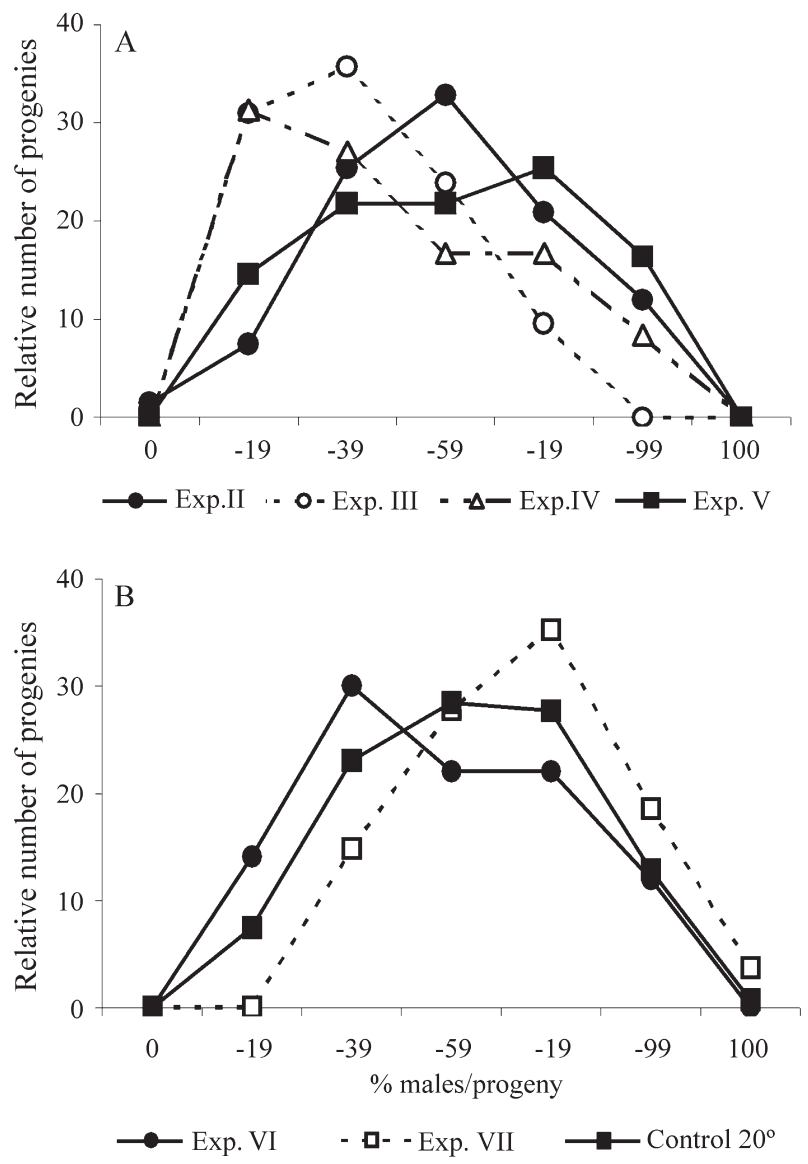

Figure 3 - Temperature-shift experiments. (A) Frequency distributions of progeny sex-ratios produced by females shifted to high temperatures according to the protocols shown in Figure 1. Skewed sex-ratio distributions were only observed in experiments III and IV. (B) Frequency distributions of progeny sex-ratios of females shifted to $12{ }^{\circ} \mathrm{C}$. A skewed distribution was observed only in experiment VII. In (B) the sex-ratio distribution at the control temperature of $20^{\circ} \mathrm{C}$ is also shown and is valid for all the experiments. The number of treated females is given in Table 1 .

As in the continuous temperature experiments both symmetric and asymmetric sex-ratio distributions were found in the temperature-shift treatments. Symmetric distributions found in continuous $\left(18{ }^{\circ} \mathrm{C} ; 20^{\circ} \mathrm{C}\right)$ and in the temperature-shift experiments (experiments II and V), were compared (regardless of experiment or temperature) but produced a non-significant heterogeneity chi-squared value $\left(\chi^{2}=16.05\right.$ for $28 \mathrm{df}$ at $\left.\mathrm{p}=0.96\right)$. Similar nonsignificant differences were observed when the asymmetric distributions of the continuous temperature $\left(24{ }^{\circ} \mathrm{C}\right.$ and $28^{\circ} \mathrm{C}$ ) and temperature-shift experiments (experiments III and IV) were compared $\left(\chi^{2}=22.17\right.$ for $28 \mathrm{df}$ at $\left.\mathrm{p}=0.06\right)$ but since the significance level of the asymmetric distributions was borderline these distributions were further compared by the Kolmogorov-Smirnov test which confirmed that these results were not significant. However, the differences between the symmetric and asymmetric distributions (regardless of experiment or temperature) were highly significant $\left(\chi^{2}=102.2\right.$ for 44 df at $\left.p<0.001\right)$.
In the last series of experiments, pupa or adults were shifted to a low temperature $\left(12^{\circ} \mathrm{C}\right)$ according to the protocol of experiments VI and VII (Figure 1, Table 1). For females treated at the pupal stage (experiment VI) the sex-ratio distribution of their progenies was symmetric $(\mathrm{M} \%=47.1 \pm 26.1)$ and did not differ significantly $(\mathrm{p}>0.10)$ from the $20{ }^{\circ} \mathrm{C}$ curve (Figure $3 \mathrm{~B}$ ). However, when females were treated after emergence (experiment VII) the sex-ratio distribution was asymmetric and skewed towards males which showed an increased mean percentage of males per progeny $(\mathrm{M} \%=65.6 \pm 16.5)$ as compared to the $20{ }^{\circ} \mathrm{C}$ control (significant at $\mathrm{p}<0.041$ ). The differences between the distributions of experiment VI and VII were highly significant $(\mathrm{p}<0.001)$.

Table 1 shows the data on the fecundity of females and the survival rates of their progenies in the temperature-shift experiments. Statistical analysis revealed that there were no significant differences in fecundity between either the high or low temperature treatments and the control temperature of $20^{\circ} \mathrm{C}$ (ANOVA, $\mathrm{F}=3.823$ for $4,274 \mathrm{df}$ at $\mathrm{p}=0.10)$. Similarly, no statistical differences compared with the controls were found among the survival rates observed in the high-temperature experiments (ANOVA, $\mathrm{F}=1.961$ for $4,274 \mathrm{df}$ at $\mathrm{p}=0.1007)$. On the contrary, the survival rates in the low-temperature experiments were both significantly different from those carried out at the control temperature (ANOVA, F = 21.91 for 2, $172 \mathrm{df}$ at $\mathrm{p}<0.001)$. However, regression analysis between the survival rates and the sex-ratio of the progenies resulted in non-significant coefficients (experiment VI, $b=0.063$ for $\mathrm{p}>0.50$; experiment VII, $\mathrm{b}=0.151$ for $0.20<\mathrm{p}<0.50$ ), indicating that the skewed sex-ratios observed were not caused by differential survival of one particular sex.

The temperature-shift experiments showed that even when treatments given during a short period of the female life cycle were sufficient to cause a modification in the sex-ratio of their offspring, but only if the period at which the females were exposed included the last stages of oogenesis from middle pupa to a short period following the emergence of the adult female. In general, our data shows that when parental females were shifted to warmer temperatures there was an increase in the frequency of females in their progenies whereas when the parental females were shifted to colder temperature their progenies contained a larger proportion of males. At both high and low temperatures there was a deviation from the expected sex-ratio of 1:1 while at intermediate temperatures the sex-ratio was about $1: 1$, although the sex-ratio of individual progenies continued to be highly variable.

For the shift to high temperatures, the progeny sexratio alterations occurred only when the parental pupa plus the newly emerged parental adult female were temperature-shifted, because when only the parental pupa or the parental adult females were shifted to a high temperature there was no modification in the progeny sex-ratio. How- 
ever, for the shift to low temperatures treatment of the parental pupa alone did not alter the progeny sex-ratio but alterations were observed when the treatment was applied to parental adult females after emergence.

\section{Concluding Remarks}

It seems that temperature stress may be more important during the initial hours of the adult stage, possibly because this is when crucial processes occur in the polytrophic meroistic ovary of Sciara leading to oocyte maturation. One such processes is the massive transfer of the single nurse cell cytoplasm of each follicle to its partner oocyte, which starts soon after emergence and takes several hours to complete (Gutzeit, 1985). It may be assumed that extreme temperatures would interfere with the rate of transfer but it is not known how this could result in modifications in the oocyte putative factor(s) assumed to control differential X chromosome elimination (DuBois, 1933, Metz, 1938, Crouse, 1960, Gerbi, 1986, Perondini, 1998, Sánchez and Perondini, 1999).

In a model for the control of X-chromosome elimination, Sánchez and Perondini (1999) proposed that such a factor (or factors) may act quantitatively, as suggested by Metz (1938). Hence, it may be that alterations in the amount of such a factor, or factors, could be caused by modifications in environmental temperature. Indeed, in line with this hypothesis, our results indicate that the temperature treatment of embryos before the $\mathrm{X}$-chromosome elimination stage did not induce modifications in the progeny sex-ratio, suggesting that thermal conditions affect the production an/or distribution of such putative factors during oogenesis but have no effect on the functioning of these factors during early embryogenesis. The nature of these factors as well as their mode of action remains to be elucidated, but some indirect evidence (Perondini, 1998; Sánchez and Perondini, 1999) suggests that they may have cytoplasmic nucleic acids (RNA) in their moiety and may either act directly on the chromosome or by its translated protein.

The effect of environmental temperature on progeny sex-ratio in S. ocellaris seems to be different from that which has been described in other insects in which the sex-ratio is also modified by thermal conditions. In hymenopterans, skewing of sex-ratios induced by temperature is due to sterilization of males, promoting an oviposition that exceeds the liberation of sperm, or by differential mortality between sexes (King, 1987). In coccids, temperature also causes skewed sex-ratios, but always seems to involve a differential mortality between the sexes (James, 1937, 1938, Brown and Bennett, 1957, Nelson-Rees, 1960, Brown and Chandra, 1977). Monogenic and amphigenic species of sciarid flies seem to respond differently to thermal conditions as far as progeny sex-ratio is concerned. In the amphigenic $S$. ocellaris, the sex-ratio is clearly affected by environmental temperature, as shown in the present re- port. On the contrary, for the monogenic Sciara coprophila, Smith-Stocking (1936) observed that the only effect of low temperature was a delay in the rate of development.

These results seem to give support to the suggestion that in monogenic species such as S. coprophila the predetermination mechanism exerts more rigid genetic control, making each female able to produce only one kind of egg, either predetermined to develop into either a male or a female fly. However, in amphigenic species such as S. ocellaris predetermination seems to be the result of a more labile control mechanism, such that alterations of physiological processes within the ovaries are sufficient to induce modifications in the proportion of oocytes determined to be males or females (Sánchez and Perondini, 1999).

It should also be recalled that our experiments reported in this paper were conducted with a strain that has been maintained for many years in the laboratory and is thus expected to be genetically homogeneous due to high levels of inbreeding. Hence, the sex-ratio modifications observed may be assumed not to be the response of different genotypes to different environmental temperatures. It has been argued (Brown and DeLotto, 1957) that systems exhibiting predetermination could be adaptive under certain conditions, permitting rapid changes in sex-ratios without deleterious consequences to the individuals. The response of the amphigenic Sciara ocellaris to thermal conditions reported here seems to be in line with this hypothesis. However, since no data are available on natural populations of Sciara ocellaris, the adaptive nature of this characteristic remains to be evaluated.

\section{Acknowledgments}

This research was supported by the Brazilian agency CNPq and the European Union (Project C1I*CT94 0071). RGN and MCCC were recipients of a Master's fellowship from the Brazilian agency CAPES.

\section{References}

Agresti A (1990) Categorical Data Analysis. John Wiley, New York, $558 \mathrm{pp}$.

Arking R, Buck S, Wells RA and Pretzalff R (1988) Metabolic rates in genetically based long lived strains of Drosophila. Exp Geront 23:59-76.

Belote JM (1992) Sex determination in Drosophila melanogaster from the X: A ratio to doublesex. Dev Biol 3:319-330.

Berry RO (1941) Chromosome behavior in the germ cells and development of the gonads in Sciara ocellaris. J Morph 68:547-583.

Brown SW and Bennett FD (1957) On sex determination in the diaspine scale Pseudaulacaspis pentagona (Targ) (Coccoidea). Genetics 42:510-523.

Brown SW and Chandra HS (1977) Chromosome imprinting and the differential regulation of homologous chromosomes. In: Goldstein L and Prescott DM (eds) Cell Biology, v. 1: Genetic Mechanisms of Cells. Academic Press, NY, pp. 109-189. 
Brown SW and DeLotto G (1957) Cytology and sex-ratios of an African species of armored scale insect (CoccoideaDiaspididade). Amer Nat 93:369-379.

Bull JJ (1983) Evolution of Sex Determining Mechanisms. W.A. Benjamin Cummings, Menlo Park, 326 pp.

Carson HL (1946) The selective elimination of inversion dicentric chromatids during meiosis in the eggs of Sciara impatiens. Genetics 31:95 -113.

Crouse HV (1960) The nature of the influence of X-translocations on sex of progeny in Sciara coprophila. Chromosoma 11:146-166.

Crow J (1994) Advantages of sexual reproduction. Develop Genet 15:205-213.

DuBois AM (1933) Chromosome behavior during cleavage in the eggs of Sciara coprophila (Diptera) in relation to the problem of sex determination. Z Zellforsch Mikrosk Anat 19:595-614.

Gerbi 5 (1986) Unusual chromosome movements in sciarid flies. In: Hennig W (ed) Results and Problems in Cell Differentiation, v. 13: Germ Line - Soma Differentiation. SpringerVerlag, Berlin, pp 7 1-104.

Gutzeit HO (1985) Oosome formation during in vitro oogenesis in Bradysia tritici (syn. Sciara ocellaris). Develop Genes Evol 194:404-410.

James HC (1937) Sex-ratios and the status of the male in Pseudococcinae (Hem. Coccidae). Bull Ent Res 28:429461.

James HC (1938) The effect of humidity of the environment on sex-ratios from over-aged ova of Pseudococcus citri Risso (Hemipt. Coccidae). Proc Roy En So London A 13:73-79.

King BH (1987) Offspring sex-ratios in parasitoid wasps. Quart Rev Biol 62:367-396.

Meise M, Hilfiker-Kleiner D, Dübendorfer A, Brunner C, Nöthiger R and Bopp D (1998) Sex-lethal, the master sex-determining gene in Drosophila is not sex-specifically regulated in Musca domestica. Development 125:1487-1494.

Metz CW (1938) Chromosome behavior, inheritance and sex determination in Sciara. Amer Natur 72:485-520.

Mori L, Dessen EMB and Perondini ALP (1979) A gene that modifies the sex-ratio in a bisexual strain of Sciara ocellaris. J Heredity 42:353-357.

Müller-Holtkamp F (1995) The Sex-lethal gene homologue in Chrysomya rufifacies is highly conserved in sequence and exon-intron organization. J mol Evol 41:467-477.

Nelson-Rees WA (1960) A study of sex predetermination in the mealy bug Planococcus citri (Risso). J Exp Zool 144:111137.

Nöthiger R and Steinmann-Zwicky M (1985) Genetics of sex determination in eukaryotes. In: Hennig W (ed) Results and Problems in Cell Differentiation, v. 14: Structure and Function of Eukaryotic Chromosomes, Spring-Verlag, Berlin, pp 271-300.

Pavan C and Perondini ALP (1967) Heterozygous puffs and bands in Sciara ocellaris Comstock (1882). Exp Cell Res 48:202205 .
Perondini ALP (1998) Elimination of X chromosomes and the problem of sex determination in Sciara ocellaris. In: Chatterjee RN and Sánchez L (eds) Genome Analysis in Eukaryotes: Developmental and Evolutionary Aspects. Narosa Publ House, New Delhi, pp 149-166.

Perondini ALP and Ribeiro AF (1997) Chromosome elimination in germ cells of Sciara embryos: Involvement of the nuclear envelope. Invert Reprod Develop 32:131-141.

Perondini ALP, Gutzeit HO and Mori L (1986) Nuclear division and migration during early embryogenesis of Bradysia tritici Coquillet (syn. Sciara ocellaris) (Diptera, Sciaridae). Int J Insect Morphol Embryol 15:155-163.

Ruiz MF, Goday C, Gonzalez P and Sanchez L (2003) Molecular analysis and developmental expression of the Sex-lethal gene of Sciara ocellaris (Diptera order, Nematocera suborder). Gene Expression Patterns 3:341-346.

Saccone G, Peluso L, Artiaco D, Giordano E, Bopp D and Polito LC (1998) The Ceratitis capitata homologue of the Drosophila sex-determining gene Sex-lethal is structurally conserved, but not sex-specifically regulated. Development 125:1495-1500.

Sánchez L and Perondini ALP (1999) Sex determination in sciarid flies: A model for the control of differential X-chromosome elimination. J Theor Biol 197:247-259.

Sánchez L, Granadino B and Torres M (1994) Sex determination in Drosophila melanogaster. X-linked genes involved in the initial step of Sex-lethal activation. Develop Genet 15:251264.

Sánchez L, Lopez PP and Granadino B (1998) Early events associated with sex determination in Drosophila melanogaster. In: Chatterjee RN and Sanchez L (eds) Genome Analysis in Eukaryotes: Developmental and Evolutionary Aspects. Narosa Publ House, New Delhi, pp 98-119.

Serna E, Gorab E, Ruiz MF, Goday C, Eirin-López J and Sánchez L (2004) The gene Sex-lethal of the Sciaridae family (Order Diptera, Suborder Nematocera) and its phylogeny in dipteran flies. Genetics 168:907-921.

Sievert V, Kuhn S and Traut W (1997) Expression of the sex determining cascade genes Sex-lethal and doublesex in the phorid fly Megaselia scalaris. Genome 40:211-214.

Smith-Stocking H (1936) Genetic studies on selective segregation of chromosomes in Sciara coprophila Lintner. Genetics 21:421-443

Ullerich F-H (1975) Die genetische Grundlage der Monogenie bei der Schmeissfliege Chrysomya rufifacies (Calliphoridae, Diptera). Mol Gen Genet 125:157-172.

Ullerich F-H (1984) Analysis of sex determination in the monogenic blowfly Chrysomya rufifacies by pole cell transplantation. Mol Gen Genet 193:479-487.

White MJD (1973) Animal Cytology and Evolution. 3rd edition. Columbia Univ Press, NY, 468 pp.

Zar JH (1999) Biostatistical Analysis. 4th edition. Prentice Hall Inc, New Jersey, 620 pp.

Zotin AL (1990) Thermodynamic Bases of Biological Processes: Physiological Reactions and Adaptations. Walter Gruyter, Berlin, $324 \mathrm{pp}$

Associate Editor: Ricardo Guelerman P. Ramos. 